\title{
Proposta de um protocolo para o processamento de requisitos do cliente em empreendimentos habitacionais de interesse social
}

Proposal for a protocol for client requirements processing in low-income housing projects

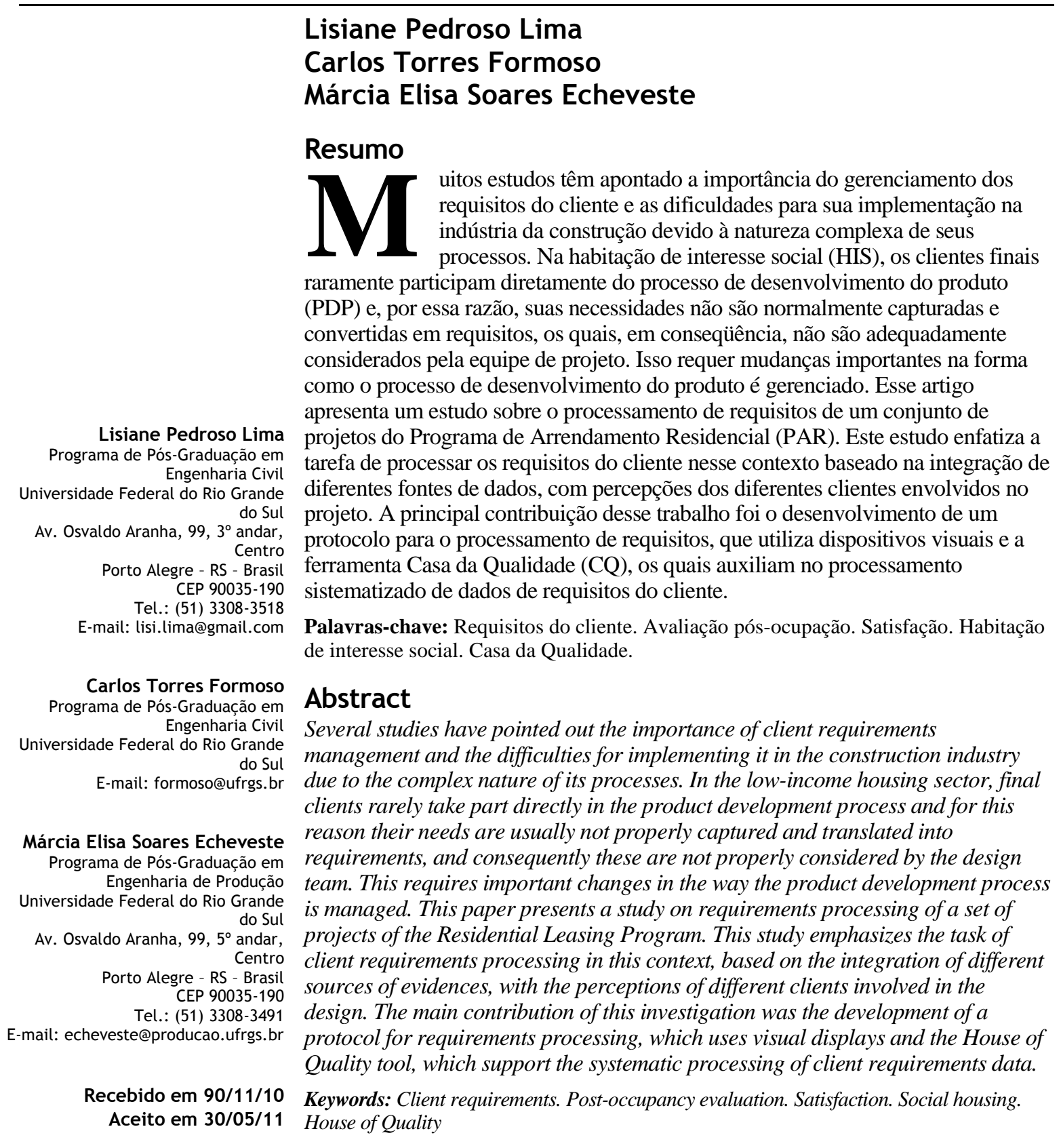

Ambiente Construído, Porto Alegre, v. 11, n. 2, p. 21-37, abr./jun. 2011. 


\section{Introdução}

No Brasil, a habitação de interesse social (HIS) é um tema de importância econômica e social que tem despertado interesse da comunidade acadêmica ao longo dos anos. Contudo, nas últimas décadas, o papel do Estado, inclusive na oferta da habitação, vem sofrendo profundas alterações. Há uma clara tendência de reduzir a intervenção direta dos agentes públicos no processo de provisão e de estimular a participação de agentes não públicos (WERNA et al., 2004; PARIS, 2007). Estabelece-se, assim, uma rede intrincada e complexa de relações entre vários agentes e o Estado, que operam de maneira fragmentada, resultando em uma ampla gama de influências políticas, sociais e culturais (WERNA et al., 2004). Nesse contexto, o gerenciamento de requisitos dos clientes adquire importância para lidar com os conflitos de requisitos, as pressões para redução de prazos e o gerenciamento de trade-offs.

Além disso, a produção habitacional brasileira tem sido muito criticada pela falta de qualidade de empreendimentos habitacionais de interesse social (EHIS). Os problemas apontados em vários estudos não são devidamente considerados na realização de novos empreendimentos, nem disponibilizados adequadamente para os tomadores de decisão, indicando que muitas oportunidades para a realização de melhorias são negligenciadas (ORNSTEIN; CRUZ, 2000; MIRON, 2002; LEITE, 2005). A baixa qualidade se deve em parte à ausência de uma avaliação sistemática de erros e acertos na produção do ambiente construído no Brasil, conduzindo à repetição das soluções adotadas sem a consequente retroalimentação e melhoria da produção desse ambiente (MEDVEDOVSKI, 2002).

Considerando que os clientes finais desse setor vêm tornando-se cada vez mais bem informados, mais exigentes e menos tolerantes aos serviços precários e aos defeitos construtivos, demanda-se por parte da indústria maior atenção a informações relacionadas às necessidades e expectativas do cliente final, para superar os problemas básicos de qualidade do setor habitacional (BARLOW; OZAKI, 2003). Logo, verifica-se a necessidade por procedimentos inovadores que possam apoiar a tomada de decisão ao longo do processo de desenvolvimento de EHIS.

\footnotetext{
${ }^{1}$ Trade-offs são escolhas a serem feitas durante a tomada de decisão. A partir desse tipo de escolha, geralmente se perde uma qualidade ou aspecto de algo, mas se ganha em troca outra qualidade ou aspecto. Isso implica que uma decisão considere tanto o lado bom quanto o lado ruim de uma escolha em particular.
}

Uma forma de enfrentar esse problema é realizar esforços de processamento de requisitos para disponibilizar as informações num formato adequado para apoiar a tomada de decisão. Contudo, um grande desafio para a equipe de desenvolvimento do produto é definir a melhor solução para atender às necessidades dos principais clientes envolvidos no processo, especialmente as do cliente final (KAMARA; ANUMBA; EVBOMWAN, 1999). Com base nessa problemática, este trabalho tem como objetivo principal propor um protocolo para o processamento de requisitos do cliente, considerando diferentes fontes de dados, quantitativas e qualitativas, baseadas na percepção do cliente final e de outros intervenientes envolvidos no desenvolvimento de EHIS

A forma de provisão habitacional selecionada para o desenvolvimento desta pesquisa foi o Programa de Arrendamento Residencial (PAR), que introduziu novos desafios ao mercado da construção habitacional brasileiro, por requerer papéis inovadores do setor público e do privado no desenvolvimento de empreendimentos, criando uma nova relação com o cliente final, até então inédita no Brasil - o arrendatário ocupa o imóvel, mas não detém a propriedade (CAIXA..., 2003). Até 31 de novembro de 2008, mais de 265 mil unidades habitacionais haviam sido contratadas pela CAIXA em todo o Brasil, beneficiando mais de 1 milhão de pessoas. Na Região Sul o número de unidades habitacionais contratadas também é expressivo, com mais de 35 mil unidades.

Este artigo apresenta o desenvolvimento de um protocolo para o processamento de requisitos do cliente de EHIS, estruturado a partir de dados que geralmente são coletados por empresas construtoras e outras organizações por meio de avaliações pós-ocupação, mas que raramente são processados e disponibilizados aos tomadores de decisão. Esta pesquisa buscou inserir ao longo do processamento a percepção de outros intervenientes do processo, a fim de que os dados não fossem unicamente embasados na percepção do cliente final. Também, como contribuições complementares, cabe destacar os dispositivos visuais desenvolvidos, uma forma ágil e simples de processar os dados, de forma a trazer maior transparência em sua análise e interpretação.

\section{Gerenciamento e processamento de requisitos}

Requisitos correspondem a funções, atributos e demais características do produto ou serviço 
requeridos por um cliente (KAMARA; ANUMBA; EVBUOMWAN, 2000b). Esses requisitos também incluem desejos coletivos, perspectivas e expectativas dos vários clientes, que constituem a principal fonte de informação para o empreendimento construtivo (KAMARA; ANUMBA; EVBUOMWAN, 2002). Em relação ao produto edifício, os requisitos dos usuários constituem uma declaração das necessidades a serem atendidas pela edificação, incluindo aspectos técnicos, fisiológicos, psicológicos e sociológicos (INTERNATIONAL..., 1982).

O gerenciamento de requisitos contempla a identificação, análise, priorização, disponibilização, controle, avaliação e armazenamento das informações sobre as necessidades e preferências dos principais clientes (MIRON, 2002) em um processo que se estende por todo o ciclo de vida da construção (PORKKA et al., 2004). A necessidade de gerenciar requisitos provém da influência dos vários intervenientes envolvidos no desenvolvimento de empreendimentos construtivos pela experiência, cultura, função, especialidade e linguagem diferenciadas e conflitantes (ULRICH; EPPINGER, 2000; ANUMBA et al., 2008).

Porém, no que pese sua importância, a aplicação do gerenciamento de requisitos em empreendimentos construtivos é geralmente insatisfatória, porque os requisitos originais não são devidamente registrados e essas informações são perdidas (HUOVILA; SERÉN, 1998). Ademais, o entendimento superficial dos requisitos do cliente, nas etapas de identificação e análise, gera um conhecimento impreciso que afeta negativamente o projeto e a produção do produto, em termos de qualidade, tempo despendido e custo (JIAO; CHEN, 2006).

Segundo Bruce e Cooper (2000), as empresas poderiam ser mais bem sucedidas se fosse dada maior atenção ao processo de captura dos requisitos nas fases iniciais do desenvolvimento do produto, para criar um conjunto consistente de informações que representasse as visões de todos os envolvidos. Além disso, torna-se necessário captar as necessidades e expectativas não explicitadas do cliente final para que essas informações forneçam subsídios para os tomadores de decisão na concepção e no projeto do produto. A falta desse conhecimento pode comprometer o resultado final do produto, resultando em tradeoffs nos quais predomina a visão dos técnicos no processo (ULRICH; EPPINGER, 2000).

$\mathrm{O}$ esforço de gerenciamento de requisitos não se limita à captura de requisitos e requer também a transformação das necessidades e expectativas dos clientes em requisitos e objetivos para o produto. Isso resulta na necessidade do processamento dos requisitos, que é um processo mais específico do gerenciamento de requisitos. O processamento dos requisitos inclui a identificação, análise e tradução dos requisitos do cliente implícitos e explícitos em soluções e especificações neutras de projeto (KAMARA; ANUMBA; EVBUOMWAN, 1999). A importância de processar os requisitos do cliente surge de vários fatores, entre eles a complexidade do cliente, a natureza das expectativas do cliente, a necessidade de compatibilizar os requisitos do cliente com os demais requisitos do empreendimento e a necessidade do trabalho integrado e colaborativo entre os profissionais envolvidos (KAMARA; ANUMBA; EVBUOMWAN, 2000a).

De acordo com Kamara, Anumba e Evbuomwan (2002), cria-se uma complexidade na determinação dos requisitos dos clientes, pois os diversos envolvidos apresentam diferentes perspectivas, que precisam ser consideradas, apesar de conflitantes. Da mesma forma, o processamento de requisitos é necessário para determinar quais expectativas dos clientes estão relacionadas ao empreendimento em desenvolvimento. Outra razão é o contexto no qual o empreendimento será implementado (KAMARA; ANUMBA; EVBUOMWAN, 2000a). Outros requisitos podem ser gerados ou derivados da necessidade do negócio da edificação proposta, tais como requisitos de obra, ambientais, legais e de construção e projeto, cujo entendimento se faz necessário, uma vez que são requisitos difíceis de ser alterados (KAMARA; ANUMBA; EVBUOMWAN, 2000a). No processamento de requisitos também deve ser considerado o trabalho colaborativo e integrado dos participantes no processo da construção (KAMARA; ANUMBA; EVBUOMWAN, 2000a). Essa característica permite que as percepções de todos os envolvidos sejam ponderadas ao longo do processo, evitandose que requisitos importantes sejam desconsiderados.

O processamento de requisitos envolve uma série de etapas. Segundo Rozenfeld et al. (2006), primeiramente, as necessidades e demandas dos clientes são organizadas, categorizadas e estruturadas, gerando os requisitos do cliente, que, por sua vez, são traduzidos em requisitos do projeto. Após a obtenção dos requisitos do projeto, são definidas as especificações-meta, que consistem em parâmetros quantitativos e qualitativos que o produto deverá ter (ROZENFELD et al., 2006).

Várias são as ferramentas apresentadas na literatura usadas para o processamento dos requisitos, sendo o QFD (Quality Function 
Deployment) a mais citada. O QFD foi projetado originalmente para captar a voz do cliente e traduzi-la em um conjunto de parâmetros de projeto que podem ser desdobrados (PRASAD, 1998). Essa ferramenta tem a sistemática de desdobrar os requisitos do cliente em detalhes críticos de projeto, construção e entrega do produto (LEPREVOST; MAZUR, 2005), além de estabelecer prioridades baseadas nos requisitos preferidos pelos clientes (KOSKELA, 2000).

O QFD é formado por quatro matrizes, mas somente a primeira será considerada neste trabalho, porque já demonstra grandes benefícios (MIGUEL, 2005). Essa matriz, chamada de Casa da Qualidade (CQ) ou Matriz da Qualidade, proporciona um guia para o processo de projeto, através do entendimento dos requisitos do cliente (qualidade demandada) e do estabelecimento de prioridades dos requisitos do projeto (características da qualidade) (MIGUEL, 2005). Assim, a CQ pode ser aplicada no contexto deste trabalho como uma ferramenta que auxilia no processamento dos requisitos.

\section{Método: desenvolvimento do protocolo}

Para o desenvolvimento do protocolo foram utilizados dados coletados na avaliação pósocupação de nove empreendimentos do PAR realizada em 2004 e 2005 em cinco cidades do Rio Grande do Sul a partir de entrevistas com o cliente final (arrendatário). O questionário utilizado apresentava a mesma estrutura para todos os empreendimentos, com exceção da avaliação da empresa construtora, que foi realizada apenas nos empreendimentos avaliados em 2004. A avaliação contemplava a coleta de dados qualitativos e quantitativos, dos quais somente os dados de satisfação e das melhores e piores características foram considerados para o desenvolvimento desta pesquisa. Esses dados foram coletados no projeto Requali, ${ }^{2}$ processados de forma mais detalhada no projeto QUALIHIS, ${ }^{3}$ ambos financiados pelo Programa de Tecnologia da Habitação (Habitare), da Financiadora de Estudos e Projetos (Finep), e resultaram na dissertação de mestrado da primeira

\footnotetext{
${ }^{2} \mathrm{O}$ projeto Requali foi desenvolvido entre 2003 e 2006 pelo Grupo de Estudos em Gerenciamento e Economia da Construção do Norie, da UFRGS, junto a outras instituições de pesquisa (UFPel, UEFS, UFC, Uece e UEL). 0 objetivo geral consistiu em estabelecer critérios e diretrizes para o gerenciamento de requisitos dos clientes em EHIS, buscando a melhoria da qualidade dos mesmos.

${ }^{3}$ O projeto QUALIHIS foi desenvolvido entre 2007 e 2009 pelo mesmo grupo de pesquisa da UFRGS com o objetivo de desenvolver um sistema de indicadores para EHIS que permitisse
}

autora (LIMA, 2007). A Tabela 1 apresenta algumas características dos empreendimentos avaliados e também da coleta de dados realizada, resultando em 298 entrevistas.

Adicionalmente, foram coletadas informações a partir de questionários e grupos focados sobre a percepção de intervenientes envolvidos nas etapas de concepção e projeto, produção e uso e ocupação do PAR. Também participaram deste estudo pesquisadores do projeto Requali, envolvidos no processo de avaliação pós-ocupação dos clientes finais de empreendimentos do PAR. Os questionários foram aplicados aos 34 participantes da pesquisa, detalhados no Quadro 1, enquanto foram realizados somente três grupos focados com os técnicos sociais, síndicos da administradora e acadêmicos, ambos intervenientes da etapa de uso e ocupação do PDP (marcados em cinza).

Os profissionais das construtoras são arquitetos ou engenheiros civis que desenvolveram projetos de empreendimentos do PAR para aprovação junto à CAIXA. Os técnicos da CAIXA são funcionários (arquitetos ou engenheiros civis) envolvidos no desenvolvimento de empreendimentos do PAR. Os síndicos são funcionários de empresa administradora de empreendimentos do PAR, geralmente requisitados pelos moradores quando surge qualquer problema no imóvel. Os técnicos sociais são profissionais contratados pela CAIXA para realizar o Trabalho Técnico Social (TTS). Os técnicos sociais da CAIXA são responsáveis pela coordenação do TTS e pela contratação de técnicos sociais que atuam junto aos moradores. Os acadêmicos são pesquisadores arquitetos ou engenheiros civis que contribuíram com sua percepção sobre a comparação do PAR com outros programas de HIS desenvolvidos no Brasil.

As informações coletadas com os clientes finais e com os intervenientes geraram o processamento dos requisitos, que ocorre ao longo de três etapas do protocolo, o que é detalhado mais adiante. A análise dos dados referentes às duas primeiras etapas do protocolo - estruturação dos requisitos do cliente e ponderação dos requisitos do cliente -, esquematizados na Figura 1, foi realizada com base no modelo interativo proposto por Miles e Huberman (1994), enquanto a análise dos dados da terceira etapa - geração dos requisitos do cliente foi realizada com o uso da CQ.

aos principais agentes envolvidos avaliar a qualidade do processo e do produto final em projetos e programas habitacionais. 
Ambiente Construído, Porto Alegre, v. 11, n. 2, p. 21-37, abr./jun. 2011.

Tabela 1 - Principais características dos empreendimentos avaliados e da coleta de dados

\begin{tabular}{|c|c|c|c|c|c|c|c|}
\hline & CIDADE & TIPO DE PAR & ÁREA & $\begin{array}{c}\mathbf{N}^{\circ} \\
\mathrm{UH} \\
\end{array}$ & $\begin{array}{c}\text { TEMPO } \\
\text { OCUPAÇÃO }\end{array}$ & $\begin{array}{c}\text { DATA } \\
\text { COLETA } \\
\end{array}$ & AMOSTRA \\
\hline $\mathbf{A}$ & Pelotas & $\begin{array}{c}\text { Normal (4 } \\
\text { pavimentos) }\end{array}$ & $46,54 \mathrm{~m}^{2}$ & 132 & 5 meses & $05 / 06 / 2004$ & 26 \\
\hline B & Pelotas & $\begin{array}{c}\text { Normal (4 } \\
\text { pavimentos) }\end{array}$ & $39,00 \mathrm{~m}^{2}$ & 160 & 16 meses & $19 / 06 / 2004$ & 32 \\
\hline $\mathbf{C}$ & Pelotas & $\begin{array}{c}\text { Normal (4 } \\
\text { pavimentos) }\end{array}$ & $39,00 \mathrm{~m}^{2}$ & 160 & 13 meses & $20 / 06 / 2004$ & 32 \\
\hline D & Porto Alegre & $\begin{array}{c}\text { Renovação } \\
\text { (14 pavimentos) }\end{array}$ & $\begin{array}{c}19,42 \text { a } 32,32 \\
\mathrm{~m}^{2}\end{array}$ & 78 & 17 meses & $\begin{array}{c}26,27 \mathrm{e} \\
28 / 06 / 2004\end{array}$ & 39 \\
\hline $\mathbf{E}$ & Canoas & $\begin{array}{c}\text { Normal (4 } \\
\text { pavimentos) }\end{array}$ & $44,30 \mathrm{~m}^{2}$ & 112 & 18 meses & 03/09/2005 & 25 \\
\hline $\mathbf{F}$ & Canoas & $\begin{array}{c}\text { Normal (4 } \\
\text { pavimentos) }\end{array}$ & $44,30 \mathrm{~m}^{2}$ & 112 & 18 meses & $03 / 09 / 2005$ & 23 \\
\hline $\mathbf{G}$ & Cachoeirinha & $\begin{array}{l}\text { Simplificado } \\
\text { (5 pavimentos) }\end{array}$ & $46,40 \mathrm{~m}^{2}$ & 360 & 5 meses & $10 / 09 / 2005$ & 74 \\
\hline $\mathbf{H}$ & Rio Grande & Normal (sobrados) & $44,30 \mathrm{~m}^{2}$ & 160 & 12 meses & $17 / 09 / 2005$ & 33 \\
\hline $\mathbf{I}$ & Porto Alegre & $\begin{array}{c}\text { Renovação (9 } \\
\text { pavimentos) }\end{array}$ & $\begin{array}{c}38,40 \text { a } 55,20 \\
\mathrm{~m}^{2}\end{array}$ & 28 & 14 meses & $\begin{array}{c}21,22 \mathrm{e} \\
23 / 09 / 2005\end{array}$ & 14 \\
\hline
\end{tabular}

\begin{tabular}{|c|c|c|c|c|c|}
\hline N & $\begin{array}{c}\text { INTERVENIENTES } \\
\text { ENVOLVIDOS }\end{array}$ & ETAPA DO PDP & $\begin{array}{c}\text { ATIVIDADES } \\
\text { DESENVOLVIDAS }\end{array}$ & $\begin{array}{c}\text { FONTES DE } \\
\text { EVIDENCIA }\end{array}$ & DATA \\
\hline 7 & $\begin{array}{c}\text { Profissionais das } \\
\text { Construtoras }\end{array}$ & $\begin{array}{c}\text { Concepção e projeto e } \\
\text { produção }\end{array}$ & $\begin{array}{c}\text { Desenvolvimento do } \\
\text { projeto e execução }\end{array}$ & $\begin{array}{c}\text { Questionário via } \\
\text { e-mail }\end{array}$ & $\begin{array}{c}\text { Dez/2006 a } \\
\text { Jan/2007 }\end{array}$ \\
\hline 5 & Técnicos da CAIXA & Concepção e projeto & Aprovação do projeto & $\begin{array}{c}\text { Questionário via } \\
\text { e-mail }\end{array}$ & $\begin{array}{c}\text { Dez/2006 a } \\
\text { Jan/2007 }\end{array}$ \\
\hline 7 & $\begin{array}{c}\text { Síndicos da } \\
\text { Administradora }\end{array}$ & Uso e ocupação & Manutenção e operação & $\begin{array}{c}\text { Grupo focado e } \\
\text { questionário }\end{array}$ & $16 / 11 / 2006$ \\
\hline 9 & Técnicos Sociais & Uso e ocupação & Trabalho Técnico Social & $\begin{array}{c}\text { Grupo focado e } \\
\text { questionário }\end{array}$ & $14 / 12 / 2006$ \\
\hline 6 & Acadêmicos & Uso e ocupação & Avaliação pós-ocupação & $\begin{array}{c}\text { Grupo focado e } \\
\text { questionário }\end{array}$ & $16 / 01 / 2007$ \\
\hline
\end{tabular}

Quadro 1 - Principais características da coleta de dados realizada com os intervenientes Nota: $\mathrm{N}$ corresponde ao número de participantes da pesquisa.

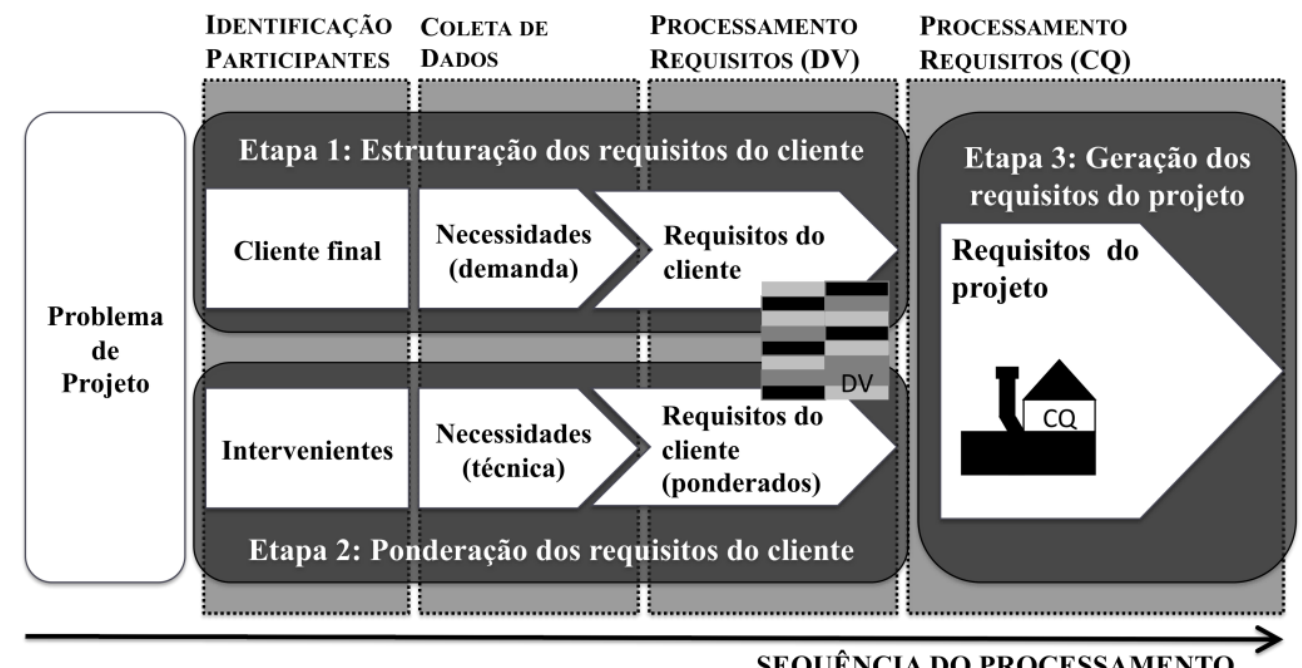

Figura 1 - Principais elementos do protocolo

SEQUÊNCIA DO PROCESSAMENTO 
As informações coletadas com os clientes finais e com os intervenientes geraram o processamento dos requisitos, que ocorre ao longo de três etapas do protocolo, o que é detalhado mais adiante. A análise dos dados referentes às duas primeiras etapas do protocolo - estruturação dos requisitos do cliente e ponderação dos requisitos do cliente -, esquematizados na Figura 1, foi realizada com base no modelo interativo proposto por Miles e Huberman (1994), enquanto a análise dos dados da terceira etapa - geração dos requisitos do cliente foi realizada com o uso da CQ.

No modelo de Miles e Huberman (1994), a análise é dividida em três atividades que, a partir da coleta de dados, estabelecem entre si um processo cíclico interativo e contínuo, sem ordenamento definido:

(a) redução de dados;

(b) dispositivos visuais; e

(c) desenhos e verificações conclusivos.

A redução de dados constitui a primeira etapa da análise de dados, cujo processo permite a seleção, o foco, a simplificação, a abstração e a transformação dos dados coletados com o objetivo de obter algumas conclusões (MILES; HUBERMAN, 1994). Os dispositivos visuais são construções organizadas e condensadas de informações que ajudam no entendimento do estudo, proporcionando um encadeamento de ideias à medida que os dados vão sendo processados (MILES; HUBERMAN, 1994).

Por fim, os dados provenientes da percepção do cliente final e da percepção dos intervenientes foram analisados conjuntamente na $C Q$, segundo procedimentos sugeridos na literatura (HAUSER; CLAUSING, 1988; RIBEIRO; ECHEVESTE; DANILEVICZ, 2001), mas com algumas adaptações, visando a sua adequação em EHIS.

\section{Protocolo para o processamento de requisitos}

De uma maneira geral, o protocolo segue os passos para processamento de requisitos sugeridos por Rozenfeld et al. (2006). A partir de um problema de projeto, os clientes envolvidos são definidos, e suas percepções (necessidades) são identificadas e, posteriormente, analisadas a partir de uma primeira etapa de processamento, gerando os requisitos do cliente, que por sua vez serão traduzidos em requisitos do projeto. A partir desse modelo, o protocolo foi dividido em três etapas principais:

(d) estruturação dos requisitos do cliente;

(e) ponderação dos requisitos do cliente; e

(f) geração dos requisitos do projeto (Figura 1).
Na primeira etapa, chamada de estruturação dos requisitos do cliente, as percepções consideradas são as do cliente final, os usuários dos empreendimentos. As necessidades (demanda) são identificadas a partir da coleta de dados realizada com o cliente final nos nove empreendimentos do PAR, conforme apresentado na Tabela 1. Os dados considerados foram obtidos da satisfação e das melhores e piores características apontados pelo cliente final. Esses dados são então processados, analisados, estruturados e traduzidos em requisitos do cliente. $\mathrm{Na}$ segunda etapa, denominada de ponderação dos requisitos do cliente, os requisitos do cliente estabelecidos na etapa anterior são ponderados a partir da percepção dos demais intervenientes do processo, conforme apresentado no Quadro 1. As necessidades (técnicas) são obtidas a partir de uma coleta de dados complementar, por meio de questionários e grupos focados. Esses dados são então processados, analisados e ponderados. Nas primeiras duas etapas são usados dispositivos visuais (DV) para a análise dos requisitos. $\mathrm{Na}$ última etapa, intitulada geração dos requisitos do cliente, os requisitos do cliente e os requisitos ponderados são integrados num terceiro processamento, através do qual eles são traduzidos em requisitos do projeto. Nesta etapa, é utilizada a CQ.

\section{Primeira etapa do protocolo}

Primeiramente, busca-se identificar as necessidades do cliente final por meio de uma coleta de dados. Na sequência, essas necessidades são processadas e traduzidas em requisitos, que, por sua vez, são analisados com o uso de dispositivos visuais.

\section{Coleta de dados do cliente final}

A coleta de dados envolve três atividades principais:

(a) seleção dos empreendimentos a avaliar;

(b) desenvolvimento do instrumento de coleta de dados; e

(c) coleta de dados.

A seleção dos empreendimentos deve ser realizada junto aos interessados na avaliação, como órgãos responsáveis pela gestão de programas, CAIXA ou Prefeituras, empresas construtoras, entre outras, mediante reuniões e análise documental. O instrumento de coleta de dados deve ser desenvolvido em reuniões junto às instituições interessadas, a partir de uma estrutura conceitual que predefina os tipos de dados a coletar na percepção do cliente final e o escopo do produto a ser avaliado. Além disso, o agendamento da coleta 
de dados deve ser realizado junto aos responsáveis dos empreendimentos. Nas datas definidas, realizase a coleta de dados nos empreendimentos selecionados com uma equipe treinada.

\section{Processamento e análise dos requisitos oriundos dos dados de satisfação}

Esta etapa compreende três atividades principais utilizando os dados de satisfação:

(a) tabulação dos requisitos em uma base de dados;

(b) priorização dos requisitos e dos empreendimentos avaliados; e

(c) análise dos requisitos processados.

As atividades desse processamento utilizam dispositivos visuais com uso de cores para facilitar a análise dos resultados, com tons de verde para os fatores de satisfação e de vermelho para os de insatisfação. ${ }^{4} \mathrm{Na}$ parte central da matriz devem ser inseridas as respostas das entrevistas para cada requisito avaliado nos empreendimentos. Esse valor é obtido através da média aritmética ponderada, resultante da soma dos produtos do número de respostas por cada um dos cinco pesos da escala, dividida pelo número total de respostas $(\mathrm{I}=\mathrm{n} .1+\mathrm{n} .2+\mathrm{n} .3+\mathrm{n} .4+\mathrm{n} .5) / \mathrm{N}$, onde $\mathrm{I}$ é o intervalo de satisfação, n é o número de respostas dos usuários, $\mathrm{N}$ é o número total de entrevistas, e os números de 1 a 5 são os pesos.

A Tabela 2 mostra a relação dos pesos e intervalos com a escala de satisfação respectiva, tal como foi usado. Os pesos são valores referentes aos níveis de satisfação, que variam de 1 (fortemente insatisfeito) a 5 (fortemente satisfeito), e os intervalos correspondem a trechos numéricos atribuídos a cada peso e grau de satisfação. Assim, os valores são inseridos nos dispositivos visuais segundo a média e a faixa de intervalo alcançada. Por exemplo, na Figura 2, o requisito "segurança do condomínio" no empreendimento PARSPE01 alcançou a média 3,96 , compreendida no intervalo de a 4,0 , correspondente ao nível de "satisfeito".

Com base nisso, primeiramente, os requisitos são tabulados seguindo a classificação proposta no instrumento de coleta de dados. Os requisitos podem ser apresentados de duas maneiras. Ora são apresentados os requisitos de nível primário, mais gerais, que correspondem aos grandes blocos avaliados ( Figura 2), ora são apresentados os requisitos de nível secundário, mais específicos.
$\mathrm{Na}$ Figura 2, os valores inseridos na matriz correspondem à média dos grandes blocos avaliados (nível primário), obtida com os intervalos dos requisitos de nível secundário desse bloco. Por exemplo, a "adequação do espaço ao mobiliário e às atividades" foi avaliada a partir da média dos intervalos dos requisitos componentes desse bloco, entre eles dormitórios, estar e jantar, banheiro, cozinha e área de serviço. Logo, essa matriz apresenta somente o resultado geral dos grandes blocos, mantendo os resultados específicos ocultos.

$\mathrm{Na}$ sequência, os requisitos são reorganizados seguindo uma estrutura hierárquica ordenada conforme o nível de satisfação. Na parte superior, ficam os requisitos que apresentam maior satisfação, e abaixo, aqueles com índices de satisfação mais baixos. Os empreendimentos localizados mais à esquerda têm maior satisfação, e os posicionados mais à direta, maior insatisfação na avaliação do cliente final (Figura 3). Os valores correspondem à média aritmética ponderada dos requisitos avaliados, como explicado no início desta seção.

$\mathrm{Na}$ Figura 2, os valores inseridos na matriz correspondem à média dos grandes blocos avaliados (nível primário), obtida com os intervalos dos requisitos de nível secundário desse bloco. Por exemplo, a "adequação do espaço ao mobiliário e às atividades" foi avaliada a partir da média dos intervalos dos requisitos componentes desse bloco, entre eles dormitórios, estar e jantar, banheiro, cozinha e área de serviço. Logo, essa matriz apresenta somente o resultado geral dos grandes blocos, mantendo os resultados específicos ocultos.

$\mathrm{Na}$ sequência, os requisitos são reorganizados seguindo uma estrutura hierárquica ordenada conforme o nível de satisfação. Na parte superior, ficam os requisitos que apresentam maior satisfação, e abaixo, aqueles com índices de satisfação mais baixos. Os empreendimentos localizados mais à esquerda têm maior satisfação, e os posicionados mais à direta, maior insatisfação na avaliação do cliente final (Figura 3). Os valores correspondem à média aritmética ponderada dos requisitos avaliados, como explicado no início da seção.

\footnotetext{
${ }^{4}$ Com a impressão em preto e branco, o recurso das cores não pode ser claramente percebido, mas na legenda constam as cores utilizadas no dispositivo visual original.
} 
Tabela 2 - Relação entre pesos, intervalos e escalas de satisfação utilizados

\begin{tabular}{ccc}
\hline PESOS & INTERVALO & ESCALA DE SATISFAÇÃO \\
\hline 1 & $\mathbf{1 , 0}$ a $\mathbf{1 , 9}$ & Fortemente insatisfeito \\
2 & $\mathbf{2 , 0}$ a 2,9 & Insatisfeito \\
3 & $\mathbf{3}$ & Neutro \\
4 & $\mathbf{3 , 1}$ a 4,0 & Satisfeito \\
5 & $\mathbf{4 , 1}$ a 5,0 & Fortemente satisfeito \\
\hline
\end{tabular}

\begin{tabular}{|c|c|c|c|c|c|c|c|c|c|c|}
\hline REQUISITOS AVALIADOS & PARSPE01 & PARSPE02 & PARSPE03 & PARSPA01 & PARSPA02 & PARSCA01 & PARSCN01 & PARSCN02 & \begin{tabular}{|l|l|} 
PARSRG01 & \\
\end{tabular} & \begin{tabular}{|c|} 
MÉDIA \\
FATORES
\end{tabular} \\
\hline \multicolumn{11}{|c|}{\begin{tabular}{|l|} 
ATENDIMENTO PRESTADO PELA EMPRESA ADMINISTRADORA \\
\end{tabular}} \\
\hline Qualidade do atendimento da empresa administradora & 2,90 & 3,23 & 2,80 & 2,99 & 3,00 & 2,66 & 2,21 & 2,45 & 2,83 & 2,67 \\
\hline \multicolumn{11}{|l|}{ QUALIDADE DO CONDOMINIIO COMO UM TODO } \\
\hline Adequação do uso das áreas condominiais coletivas & 3,58 & 3,58 & 3,50 & 3,33 & 3,63 & 3,37 & 3,15 & 3,24 & 3,57 & 3,38 \\
\hline Segurança do condomínio & 3,96 & 3,89 & 3,08 & 3,21 & 3,67 & 3,48 & 3,44 & 3,45 & 3,87 & 3,55 \\
\hline \multicolumn{11}{|l|}{ QUALIDADE DA UNIDADE HABITACIONAL } \\
\hline Adequação do espaço ao mobiliário e às atividades & 3,40 & 3,65 & 3,30 & 2,76 & 3,49 & 3,70 & 3,46 & 3,17 & 3,80 & 3,44 \\
\hline Condiçōes naturais de conforto & 3,38 & 3,43 & 3,50 & 3,45 & 3,46 & 3,45 & 3,35 & 3,46 & 3,61 & 3,46 \\
\hline Funcionamento das instalações e das esquadrias & 3,78 & 3,84 & 3,74 & 3,54 & 3,86 & 3,71 & 3,65 & 4,11 & 3,73 & 2,75 \\
\hline Qualidade dos acabamentos & 3,12 & 3,38 & 3,29 & 3,10 & 3,23 & 3,44 & 2,61 & 2,41 & 3,66 & 3,21 \\
\hline \multirow[t]{2}{*}{ MÉDIA EMPREENDIMENTOS } & 3,45 & 3,57 & 3,32 & 3,20 & 3,48 & 3,40 & 3,12 & 3,18 & 3,58 & GERAL \\
\hline & $\begin{array}{r}\text { FOR } \\
\text { INSA } \\
\text { VERME }\end{array}$ & $\begin{array}{l}\text { ENTE } \\
\text { EITO } \\
\text { FORTE) }\end{array}$ & $\underset{\text { INS }}{\text { INS }}$ & $\begin{array}{l}\text { EITO } \\
\text { FRACO, }\end{array}$ & $\underset{B B A S}{N E U}$ & $\begin{array}{l}\text { TRO } \\
\text { INCO }\end{array}$ & $\underset{N A K}{S A}$ & $\begin{array}{l}\text { FEITO } \\
\text { ERACO) }\end{array}$ & $\begin{array}{c}F O R \\
\text { SAR } \\
\text { CIER }\end{array}$ & $\begin{array}{l}\text { EENTE } \\
\text { SFETO } \\
\text { FORTE) }\end{array}$ \\
\hline
\end{tabular}

Figura 2 - Representação dos fatores mais gerais de satisfação

\begin{tabular}{|c|c|c|c|c|c|c|c|c|c|c|c|}
\hline \multirow{2}{*}{\multicolumn{2}{|c|}{ REQUISITOS AVALIADOS }} & 1 & 2 & \multirow{3}{*}{\begin{tabular}{|c|}
3 \\
PARSPA02 \\
3,86 \\
\end{tabular}} & \multirow{3}{*}{\begin{tabular}{|c|}
4 \\
PARSPE05 \\
4,19
\end{tabular}} & \multirow{3}{*}{$\begin{array}{c}5 \\
\text { PARSCA02 } \\
4,07\end{array}$} & \multirow{3}{*}{\begin{tabular}{|c|}
6 \\
PARSPE02 \\
4,00 \\
\end{tabular}} & \multirow{3}{*}{\begin{tabular}{|c|}
7 \\
PARSPA01 \\
3,97 \\
\end{tabular}} & \multirow{3}{*}{\begin{tabular}{|c|}
8 \\
PARSCN02 \\
3,74 \\
\end{tabular}} & \multirow{3}{*}{\begin{tabular}{|c|}
9 \\
PARSCN01 \\
3,64 \\
\end{tabular}} & \\
\hline & & \multirow{2}{*}{\begin{tabular}{|c|} 
PARSRG01 \\
3,73 \\
\end{tabular}} & \multirow{2}{*}{$\begin{array}{c}\text { PARSPE01 } \\
4,06\end{array}$} & & & & & & & & \\
\hline 1 & Aparência externa do condomínio como um todo & & & & & & & & & & \begin{tabular}{|c|c|} 
MÉDIA \\
FATORES
\end{tabular} \\
\hline 2 & Iluminação natural dos ambientes & 3,94 & 3,88 & 3,93 & 4,04 & 3,95 & 3,88 & 3,82 & 4,26 & 3,92 & 3,94 \\
\hline 3 & Funcionamento das instalações hidrossanitárias & 3,76 & 4,03 & 3,86 & 3,69 & 3,89 & 3,50 & 3,85 & 4,04 & 3,84 & 3,83 \\
\hline 4 & Banheiros & 4,06 & 4,06 & 3,71 & 3,50 & 4,01 & 4,09 & 2,79 & 3,57 & 4,04 & 3,78 \\
\hline 5 & Funcionamento das instalações elétricas & 3,97 & 4,00 & 3,79 & 3,65 & 3,43 & 3,84 & 3,74 & 4,04 & 3,96 & 3,77 \\
\hline 6 & Estar e jantar & 3,76 & 4,03 & 3,71 & 4,00 & 3,74 & 3,72 & 3,26 & 3,96 & 3,88 & 3,76 \\
\hline 7 & Funcionamento das janelas & 3,64 & 3,78 & 3,93 & 3,85 & 3,92 & 3,72 & 3,31 & 4,09 & 3,36 & 3,73 \\
\hline 8 & Dormitórios & 4,06 & 3,88 & 3,79 & 4,00 & 3,85 & 3,47 & 3,13 & 3,61 & 3,64 & 3,71 \\
\hline 9 & Funcionamentos das portas & 3,58 & 3,53 & 3,86 & 3,92 & 3,59 & 3,91 & 3,28 & 4,26 & 3,44 & 3,66 \\
\hline 10 & Guarita & 3,85 & 3,84 & $>$ & 4,04 & 3,50 & 2,75 & $>$ & 3,78 & 3,84 & 3,61 \\
\hline \multirow{2}{*}{11} & Segurança dos acessos principais do condomínio & 3,88 & 3,94 & $>$ & 4,04 & 3,53 & 3,03 & $\infty$ & 3,43 & 3,48 & 3,60 \\
\hline & Temperatura interna no verão & 3,70 & 3,63 & 3,79 & 3,81 & 3,28 & 3,88 & 3,56 & 3,48 & 3,92 & 3,60 \\
\hline 12 & Segurança dos acessos principais dos blocos & $><$ & 3,84 & 3,36 & 3,88 & 3,42 & 3,50 & 3,36 & 3,57 & 3,52 & 3,54 \\
\hline 13 & Segurança do condomínio como um todo & 3,88 & 4,13 & 3,71 & 4,19 & 3,50 & 2,94 & 3,38 & 2,87 & 3,16 & 3,53 \\
\hline 14 & Entrada do bloco & $>$ & 3,78 & 3,21 & 3,62 & 3,30 & 3,84 & 3,41 & 3,74 & 3,08 & 3,48 \\
\hline 15 & Escadas e corredores & $>$ & 4,03 & 4,00 & 3,85 & 2,73 & 3,78 & 3,72 & 3,39 & 3,40 & 3,46 \\
\hline \multirow{2}{*}{16} & Segurança à entrada de terceiros no apartamento & 3,88 & 3,69 & 3,93 & 3,65 & 3,45 & 3,19 & 2,90 & 3,61 & 3,20 & 3,45 \\
\hline & Temperatura interna no inverno & 3,67 & 3,16 & 3,79 & 2,77 & 3,74 & 3,34 & 3,77 & 3,04 & 3,24 & 3,45 \\
\hline 17 & Praça infantil & 3,39 & 3,59 & $\infty_{1}$ & 3,73 & 3,68 & 3,22 & $>$ & 3,04 & 2,92 & 3,44 \\
\hline 18 & Tetos de banheiro, cozinha e área de serviço & 3,85 & 3,53 & 3,64 & 3,19 & 3,65 & 3,16 & 3,54 & 2,61 & 2,56 & 3,38 \\
\hline \multirow{2}{*}{19} & Paredes de banheiro, cozinha e área de serviço & 3,70 & 3,44 & 3,57 & 3,58 & 3,47 & 3,09 & 3,10 & 3,09 & 2,92 & 3,34 \\
\hline & Cozinha & 3,64 & 3,34 & 3,57 & 3,08 & 3,64 & 3,03 & 3,08 & 2,83 & 3,44 & 3,34 \\
\hline 20 & Salão de festas & 3,97 & 3,47 & 3,43 & 3,65 & 3,31 & 3,59 & 2,23 & 3,26 & 3,12 & 3,31 \\
\hline 21 & Área com vegetação (área verde) & 3,39 & 3,53 & $>$ & 2,88 & 3,42 & 3,44 & $>$ & 2,61 & 3,08 & 3,27 \\
\hline 22 & Pisos de banheiro, cozinha e área de serviço & 3,76 & 3,41 & 3,57 & 3,04 & 3,58 & 3,50 & 2,54 & 2,26 & 2,52 & 3,20 \\
\hline 23 & Estacionamentos & 3,36 & 3,53 & $\infty<$ & 3,15 & 3,08 & 3,31 & $>$ & 2,91 & 2,84 & 3,18 \\
\hline 24 & Pisos de dormitórios & 3,70 & 3,31 & 2,64 & 2,85 & 3,31 & 3,50 & 3,41 & 2,09 & 2,56 & 3,16 \\
\hline 25 & Pisos de estar e jantar & 3,76 & 3,34 & 2,79 & 3,04 & 3,31 & 3,53 & 2,90 & 2,17 & 2,48 & 3,13 \\
\hline 26 & Paredes e tetos dos dormitórios, estar e jantar & 3,21 & 3,25 & 3,14 & 3,04 & 3,31 & 2,94 & 3,10 & 2,22 & 2,60 & 3,05 \\
\hline 27 & Áreas esportiva & 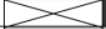 & 2,66 & 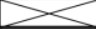 & 3,58 & $>$ & 2,84 & $>$ & $>$ & $>$ & 2,99 \\
\hline 28 & Atendimento na prestação de serviços & 3,03 & 3,06 & 2,93 & 2,85 & 3,09 & 2,69 & 2,85 & 2,70 & 2,44 & 2,89 \\
\hline 29 & Nível de ruído & 3,15 & 3,06 & 2,36 & 2,92 & 2,82 & 2,91 & 2,64 & 3,04 & 2,32 & 2,83 \\
\hline 30 & Comunicação & 3,03 & 3,41 & 2,71 & 2,96 & 2,46 & 2,91 & 3,13 & 2,74 & 2,24 & 2,82 \\
\hline 31 & Transparência na prestação de contas & 3,03 & $\infty<$ & 2,57 & $\infty<$ & 2,73 & $>$ & $\infty<$ & 2,43 & 2,12 & 2,64 \\
\hline 32 & Área de serviço & 3,48 & 2,94 & 2,64 & 2,42 & 3,26 & 2,19 & 1,54 & 1,91 & 2,28 & 2,62 \\
\hline & Custo do condomínio & 2,24 & $>$ & 3,79 & $><$ & 2,34 & $>$ & $>$ & 1,91 & 2,04 & 2,34 \\
\hline \multicolumn{2}{|r|}{ MÉDIA EMPREENDIMENTOS } & 3,58 & 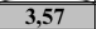 & 3,48 & 3,45 & 3,40 & 3,32 & 3,20 & 3,18 & 3,12 & GERAL \\
\hline & LEGEN & $\begin{array}{r}F O R \\
\text { INSA } \\
\text { WERME }\end{array}$ & $\begin{array}{l}\text { ENTE } \\
\text { EITO } \\
\text { FORTE) }\end{array}$ & INSA & $\begin{array}{l}\text { SFEITO } \\
\text { O FRACO) }\end{array}$ & & & $\begin{array}{r}S A T \\
\text { VER }\end{array}$ & EITO & $\begin{array}{c}\text { FORTEI } \\
\text { SATISI } \\
\text { (VERDE }\end{array}$ & $\begin{array}{l}\text { MENTE } \\
\text { FEITO } \\
\text { FORTE) }\end{array}$ \\
\hline
\end{tabular}

Figura 3 - Priorização dos requisitos e empreendimentos avaliados 
A análise desses dispositivos possibilita um entendimento conjunto dos requisitos através de:

(a) identificação dos requisitos que afetam a satisfação do cliente final;

(b) comparação visual entre esses requisitos;

(c) comparação dos resultados entre os empreendimentos;

(d) classificação dos requisitos que alcançaram maiores médias de satisfação; e

(e) classificação dos empreendimentos que apresentaram maiores médias de satisfação.

\section{Processamento e análise dos requisitos oriundos das melhores e piores características}

Essa etapa apresenta três atividades principais utilizando as melhores e piores características apontadas pelos arrendatários:

(a) processamento individual das necessidades;

(b) processamento conjunto dos requisitos;

(c) agrupamento dos requisitos; e

análise dos requisitos processados.

O processamento individual das necessidades consiste na tradução dessas necessidades em requisitos do cliente. $\mathrm{O}$ processo começa com a hierarquização das necessidades em categorias, que são traduzidas em requisitos do cliente a partir da padronização de linguagem. Essa primeira hierarquização deve abranger:

(a) a classificação das necessidades em categorias;

(b) seu agrupamento por categorias; e

(c) a adaptação de sua linguagem.

A classificação neste trabalho consiste na redistribuição das necessidades em categorias conforme o grau de similaridade entre elas, permitindo identificar as categorias apontadas como positivas e negativas pelos usuários em cada empreendimento. $\mathrm{O}$ agrupamento consiste na reunião das necessidades previamente classificadas, em categorias predeterminadas relacionadas ao empreendimento, possibilitando entender o que cada categoria expressa em termos de necessidades do cliente final. O produto dessa atividade é uma primeira estrutura hierárquica das necessidades identificadas na coleta de dados. A estrutura hierárquica consiste na representação gerada a partir de etapas preliminares de classificação, agrupamento e ordenação das necessidades, agora organizadas e dispostas hierarquicamente. A adaptação de linguagem busca criar uma linguagem única e padronizada dessas necessidades, que a partir desse ajuste passam a ser chamadas de requisitos do cliente. Como consequência, os requisitos não apresentam mais repetições e têm seu número reduzido para as etapas seguintes de processamento.

O processamento conjunto dos requisitos é realizado em duas etapas:

(a) classificação e ordenação; e

(b) agrupamento em uma matriz.

A ordenação consiste no arranjo dos requisitos, subordinado a um atributo mensurável predeterminado. Nesse caso, a ordenação é realizada pela importância (número de citações realizadas pelos arrendatários). Os requisitos são também classificados e ordenados em uma estrutura de árvore lógica. Através desse agrupamento, cria-se uma estrutura hierárquica que apresenta, de forma ordenada, todos os requisitos relacionados entre si. Esse agrupamento segue a lógica de desdobramento da qualidade, base do QFD, que consiste em detalhar em diferentes níveis as qualidades demandadas da mais geral (nível primário), que são também desdobradas em níveis mais específicos (secundário e terciário).

$\mathrm{Na}$ sequência, cria-se um dispositivo visual em forma de matriz, para a inserção dos requisitos. São criadas duas matrizes, uma para os requisitos apontados como positivos (Figura 4$)^{5}$ e outra para os mencionados como negativos. Os valores da parte central da matriz correspondem ao número de citações realizadas pelos entrevistados para os requisitos e empreendimentos respectivos. Também são inseridos os totais e percentuais, estes detalhados na própria figura. Dentro de cada categoria, os requisitos são ordenados a partir dos mais citados. Os requisitos são dispostos de forma ordenada, ficando na parte superior da matriz as categorias mais citadas pelos arrendatários.

A análise desse dispositivo proporciona um entendimento conjunto dos requisitos:

(a) comparação visual entre as duas matrizes (resultados positivos versus negativos);

(b) classificação dos requisitos em relação aos empreendimentos - pode ser pontual ou geral;

(c) hierarquização dos requisitos e das categorias; e

(d) somatórios e porcentagens das citações dos requisitos e das categorias em cada empreendimento.

${ }^{5}$ Pela limitação de espaço, não são apresentados todos os requisitos, somente alguns para propiciar o entendimento desse dispositivo visual. 
Além disso, o dispositivo visual também possibilita análises mais específicas, através das quais se tem um entendimento mais aprofundado de determinadas partes da matriz:

(a) comparação dos requisitos em cada categoria; e

(b) comparação das categorias citadas como positivas e negativas (cruzamento de dados das duas matrizes).

Com essa estrutura, pode-se visualizar todos os requisitos citados pelo cliente final, tanto os mais abrangentes como os mais pontuais, e a relação destes com os empreendimentos.

$\mathrm{Na}$ sequência, o agrupamento dos requisitos busca reunir todos os requisitos em uma árvore lógica, para a construção da CQ. Para a árvore de requisitos são consideradas as recomendações de Ribeiro, Echeveste e Danilevicz (2000):

(a) as reclamações e qualidades negativas devem ser transformadas em qualidades positivas, com um adjetivo mais substantivo; (b) a árvore lógica deve ser equilibrada, ou seja, o número de itens terciários associados a cada item do nível secundário deve ser aproximadamente o mesmo; e

(c) a árvore lógica deve ser composta de itens mutuamente exclusivos.

A árvore lógica de requisitos do cliente final possibilita agregar as informações provenientes das melhores e piores características, sendo esclarecido, de forma sintética, o que cada requisito do cliente final abrange em termos de necessidades.

\section{Segunda etapa do protocolo}

O principal objetivo da segunda etapa do protocolo é definir uma ponderação dos requisitos do cliente final com base na percepção de outros intervenientes do processo de desenvolvimento de EHIS. Primeiramente, realiza-se uma coleta de dados com esses intervenientes e, na sequência, os dados são processados e analisados com o uso de dispositivos visuais.

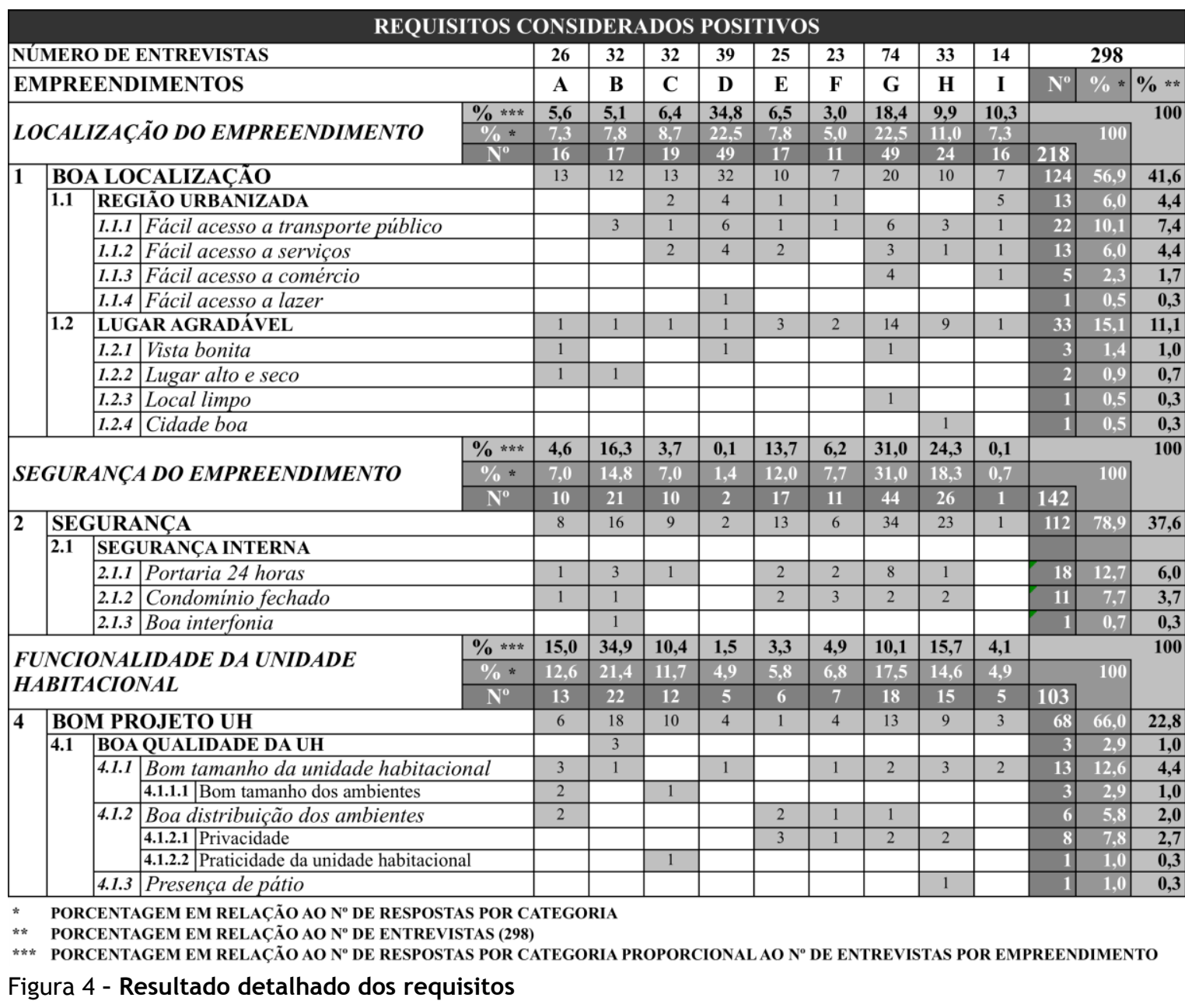

30 Lima, L. P.; Formoso, C. T.; Echeveste, M. E. S. 


\section{Coleta de dados complementares}

A coleta de dados complementares envolve três atividades principais:

(a) seleção dos principais intervenientes envolvidos no desenvolvimento do produto avaliado;

(b) desenvolvimento de instrumentos de coleta de dados qualitativos e quantitativos; e

(c) coleta de dados, como mostra a Figura 5.

Para a seleção dos intervenientes envolvidos, é preciso considerar aqueles que desempenham papel importante no desenvolvimento do produto ou cuja atuação interfere na satisfação do cliente final. A escolha é realizada em conjunto por meio de análise documental e de reuniões entre pesquisadores e instituições interessadas na pesquisa.

Na sequência, são desenvolvidos dois instrumentos para a coleta de dados. O primeiro, para a coleta de dados qualitativos, constitui-se de um roteiro estruturado para ser aplicado por meio de grupos focados - fonte de evidência adequada para reunir vários representantes de um mesmo grupo de intervenientes num mesmo encontro e possibilitar uma discussão entre eles, de forma interativa. $\mathrm{O}$ objetivo é entender como os intervenientes compreendem os principais requisitos do cliente final identificados na avaliação pós-ocupação.

O instrumento de coleta de dados quantitativos é desenvolvido considerando os requisitos do cliente final listados na árvore lógica de requisitos, na etapa de "agrupamento dos requisitos" da primeira etapa do protocolo. $\mathrm{Na}$ primeira parte do instrumento, uma lista de requisitos (secundários), classificada em diferentes categorias, é listada para ser avaliada pelos intervenientes conforme a importância. Na segunda parte do instrumento, também conforme o nível de importância, as grandes categorias de requisitos (primários) são listadas para ser ordenadas pelos intervenientes.
O agendamento da coleta de dados deve ser realizado junto aos intervenientes que participarão da coleta de dados. Nas datas definidas, faz-se a coleta de dados com os diferentes intervenientes, sendo realizado primeiramente o grupo focado e, na sequência, a aplicação do questionário.

\section{Processamento e análise dos requisitos oriundos dos dados complementares}

Esse processamento consiste em duas atividades principais:

(a) organização do banco de dados; e

(b) análise geral da percepção dos intervenientes.

Primeiramente, cria-se um banco de dados para a organização e o processamento dos requisitos com o uso de dispositivos visuais. Posteriormente, criase um dispositivo para os requisitos de nível primário e, na sequência, outro, para os de nível secundário. A análise realizada para os requisitos primários e secundários é a mesma: através dos dispositivos visuais, o que possibilita, na sequência, uma análise cruzada para entender a relação entre eles. Abaixo, na Figura 6, um exemplo de um dispositivo visual dos cinco requisitos primários classificados como os mais importantes para cada grupo de intervenientes e para os usuários.

A análise dos dispositivos visuais possibilita uma análise conjunta das diferentes percepções dos intervenientes, permitindo entender as percepções de cada um, geralmente relacionadas com a atividade que desempenham ao longo do processo. Além disso, as percepções dos intervenientes podem ser comparadas com as dos usuários, a fim de identificar semelhanças e diferenças existentes. Por sua vez, a análise mais detalhada dos requisitos secundários ajuda no entendimento da priorização dada aos requisitos primários. Por exemplo, lugar agradável e fácil acesso a transporte público (requisitos secundários) ajudam a explicar a importância do requisito (primário) localização.

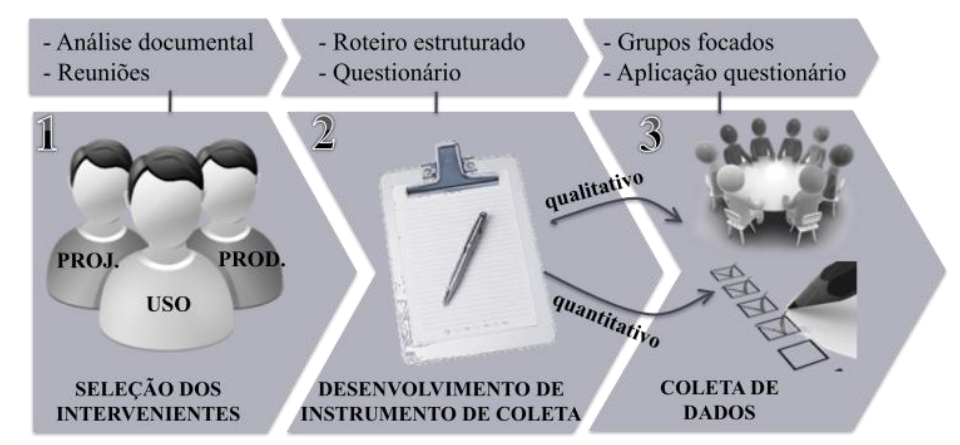

Figura 5 - Esquema para a coleta de dados complementares 
A análise desses dispositivos visuais, aliada aos resultados dos grupos focados, ajuda a entender as diferentes percepções dos intervenientes avaliados. Com base nisso, considerando-se a importância dos requisitos, é possível ordená-los. Esse resultado é importante porque a ponderação dos requisitos do cliente será aplicada na próxima etapa de processamento com o uso da CQ.

A análise desses dispositivos visuais, aliada aos resultados dos grupos focados, ajuda a entender as diferentes percepções dos intervenientes avaliados. Com base nisso, considerando-se a importância dos requisitos, é possível ordená-los. Esse resultado é importante porque a ponderação dos requisitos do cliente será aplicada na próxima etapa de processamento com o uso da CQ.

\section{Terceira etapa do protocolo}

O principal objetivo da terceira etapa do protocolo é definir uma lista de requisitos de projeto. Para tanto, os dados gerados nas etapas anteriores (lista de requisitos e ponderação dos requisitos) serão processados através da CQ (Figura 7), a partir de seis etapas: (a) definição dos requisitos do cliente;

(b) definição dos requisitos do projeto (visão técnica);

(c) relação entre requisitos do cliente final e requisitos do projeto;

(d) priorização dos requisitos do cliente final;

(e) relação entre requisitos do projeto; $\mathrm{e}$

(f) importância dos requisitos do projeto.

A definição dos requisitos do cliente considera os requisitos classificados na árvore lógica desenvolvida na primeira etapa do protocolo. Essa etapa permite a seleção dos requisitos mensuráveis e sua importância, e está limitada aos requisitos relacionados ao produto habitacional - os requisitos dos serviços prestados foram excluídos do processamento para reduzir o escopo. Essa etapa de processamento envolve duas atividades principais:
(a) seleção dos requisitos mensuráveis; e
(b) priorização dos requisitos mensuráveis.

\begin{tabular}{|c|c|c|c|c|c|c|}
\hline ORDEM & USUÁRIOS & SÍNDICOS & T. SOCIAIS & T. CAIXA & PROF. CONSTR. & ACADEMICOS \\
\hline 1 & Localização (rosa) & $\begin{array}{c}\text { Programa } \\
\text { (amarelo) }\end{array}$ & $\begin{array}{c}\text { Administração } \\
\text { (marrom) }\end{array}$ & $\begin{array}{c}\text { Programa } \\
\text { (amarelo) }\end{array}$ & $\begin{array}{c}\text { Programa } \\
\text { (amarelo) }\end{array}$ & Localização (rosa) \\
\hline 2 & $\begin{array}{c}\text { Vida em } \\
\text { condomínio (lilás) }\end{array}$ & $\begin{array}{c}\text { Problemas } \\
\text { construtivos } \\
\text { (vermelho) }\end{array}$ & $\begin{array}{c}\text { Problemas } \\
\text { construtivos } \\
\text { (vermelho) }\end{array}$ & $\begin{array}{c}\text { Problemas } \\
\text { construtivos } \\
\text { (vermelho) }\end{array}$ & $\begin{array}{c}\text { Problemas } \\
\text { construtivos } \\
\text { (vermelho) }\end{array}$ & $\begin{array}{c}\text { Programa } \\
(\text { amarelo) }\end{array}$ \\
\hline 3 & Segurança (laranja) & Segurança (laranja) & $\begin{array}{c}\text { Programa } \\
\text { (amarelo) }\end{array}$ & $\begin{array}{c}\text { Projeto da UH } \\
\text { (azul) }\end{array}$ & $\begin{array}{c}\text { Projeto do } \\
\text { condomínio (verde) }\end{array}$ & Segurança (laranja) \\
\hline 5 & $\begin{array}{c}\text { Administração } \\
\text { (marrom) }\end{array}$ & $\begin{array}{c}\text { Qualidade dos } \\
\text { materiais (cinza) }\end{array}$ & $\begin{array}{c}\text { Condições de } \\
\text { conforto (roxo) }\end{array}$ & $\begin{array}{c}\text { Qualidade dos } \\
\text { materiais (cinza) }\end{array}$ & $\begin{array}{c}\text { Qualidade dos } \\
\text { materiais (cinza) }\end{array}$ & $\begin{array}{c}\text { Qualidade dos } \\
\text { materiais (cinza) }\end{array}$ \\
\hline Projeto da UH \\
(azul)
\end{tabular}

Figura 6 - Percepção dos intervenientes e usuários quanto à importância dos requisitos primários

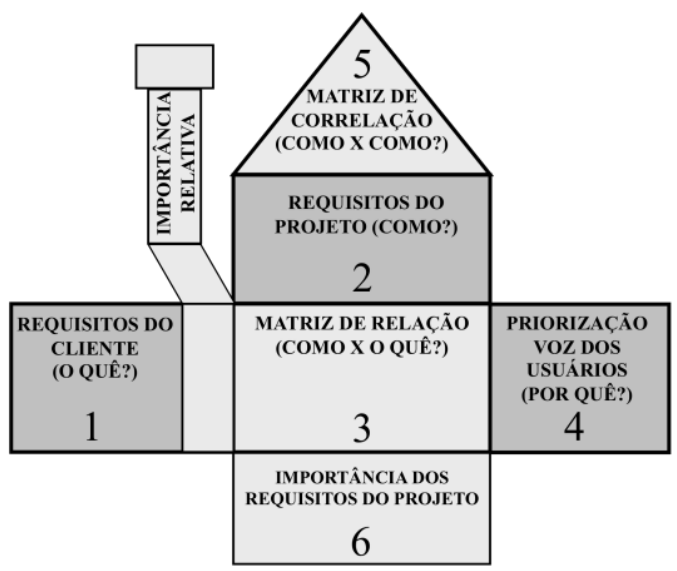

Figura 7 - Casa da Qualidade

Fonte: Hauser e Clausing (1988). 


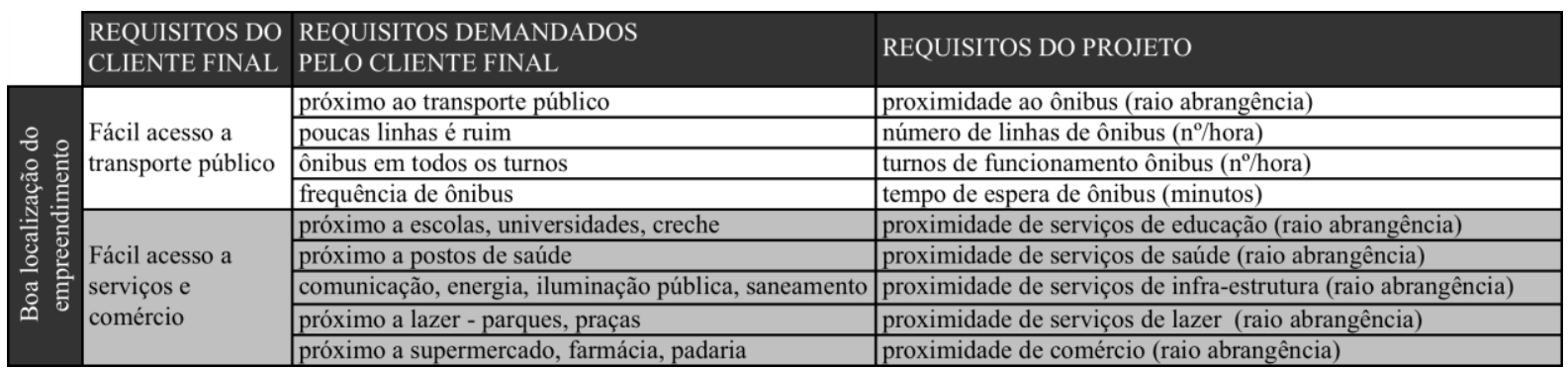

Figura 8 - Tradução de requisitos do cliente em requisitos do projeto (localização do empreendimento)

Somente devem ser considerados os elementos passíveis de se tornarem mensuráveis para julgar a qualidade (AKAO, 1996). Dessa forma, a árvore lógica dos requisitos é desdobrada em dois grupos:

(a) requisitos mensuráveis; e

(b) requisitos para decisão de projeto (não mensuráveis).

Somente os primeiros entram no processamento, enquanto os demais servem para auxiliar na tomada de decisão (RIBEIRO; ECHEVESTE; DANILEVICZ, 2001). A partir da seleção dos requisitos mensuráveis, estes são priorizados conforme o número de citações feitas pelos arrendatários. Todos os requisitos mensuráveis e as respectivas porcentagens são então insertos na primeira coluna da CQ.

A definição dos requisitos do projeto é realizada a partir da percepção dos arrendatários. Para cada requisito do cliente, analisam-se as melhores e piores características originais, conforme a linguagem dos arrendatários, a fim de identificar as necessidades demandadas. Para melhor entendimento, a Figura 8 apresenta um exemplo desse desdobramento para o requisito boa localização do empreendimento, quanto à facilidade de acesso a transporte público e a serviços e comércio.

A Figura 8 traz elementos que são insertos na CQ, tanto os requisitos do cliente como os de projeto. O exemplo ilustra como foi realizada a tradução dos requisitos do cliente em requisitos de projeto. Conforme os requisitos do cliente são introduzidos na primeira coluna da CQ (1), ${ }^{6}$ para cada um é relacionado, no mínimo, um requisito de projeto, os quais vão sendo dispostos um a um na linha superior da CQ (2). ${ }^{7}$ Por exemplo, é importante para o cliente final a proximidade ao transporte público, logo o requisito do projeto implicado é o raio de abrangência entre o empreendimento e o ponto de ônibus. Ao final do processamento, podese chegar a uma especificação de projeto, dizendo

\footnotetext{
${ }^{6}$ Esse número corresponde ao ilustrado na Figura 7.

${ }^{7}$ Idem ao item anterior.
}

qual o valor ou o intervalo mais adequado desse raio de abrangência.

A partir dessa análise, estabelece-se um grupo de discussão para a avaliação dos requisitos de projeto identificados. Em seguida, os requisitos do projeto são ajustados considerando-se os apontamentos feitos pela equipe. Posteriormente, eles são agrupados conforme critérios de medição para inserção na CQ.

A relação entre requisitos do cliente final e requisitos do projeto é realizada com o uso de valores de progressão geométrica, apresentados por Kamara, Anumba e Evbuomwan (1999). Para cada requisito do projeto que estabelece uma relação forte com determinado requisito do cliente, marca-se 9; para relação moderada, 3; e para relação fraca, 1. Essa etapa possibilita identificar os requisitos do projeto que afetam os requisitos do cliente final e a intensidade dessa relação. $\mathrm{O}$ estabelecimento dessas relações é importante porque elas influenciam a priorização dos requisitos do projeto - quanto mais relações fortes os atributos têm, mais importância eles adquirem.

A priorização dos requisitos do cliente final busca a integração das percepções dos diferentes intervenientes na avaliação dos requisitos do cliente final. Foram necessárias alterações conceituais e de procedimentos no uso da CQ. A avaliação competitiva é chamada neste trabalho de avaliação comparativa, a qual é mensurada a partir da percepção dos acadêmicos. Quanto à avaliação estratégica, foram consideradas as percepções dos técnicos da Caixa, dos profissionais das construtoras, dos síndicos e dos técnicos sociais. O principal resultado dessa matriz é a ponderação dos requisitos do cliente final a partir da avaliação estratégica e comparativa dos intervenientes envolvidos no processo, resultando em nova classificação de importância dos requisitos.

Para a relação entre os requisitos do projeto, é utilizada a simbologia sugerida por Ribeiro, Echeveste e Danilevicz (2000): (=), (-), (+) e (*), que significam respectivamente relações negativa forte, negativa fraca, positiva fraca e positiva forte. 
A importância dessa etapa é a identificação da relação e da intensidade existente entre os requisitos do projeto, ou seja, evidencia como cada requisito interfere nos demais. Essa relação demonstra os requisitos conflitantes entre si e que, por essa razão, devem ser considerados na gestão de trade-offs no desenvolvimento do projeto, tornando o processo de tomada de decisão mais racional.

Na importância dos requisitos do projeto é gerada a priorização desses requisitos. Essa etapa finaliza o processo de construção da CQ, cujas etapas influenciam diretamente em seu resultado final. Uma próxima etapa seria a geração de especificações meta do projeto, a qual não entra no escopo deste artigo.

\section{Discussão}

O protocolo proposto foi avaliado de duas formas. Os dispositivos visuais, resultantes do processamento dos requisitos, foram utilizados em 8 workshops e seminários realizados em conjunto com intervenientes do Programa PAR, incluindo técnicos da Caixa, representantes de empresas construtoras e empresas administradoras de imóveis, e acadêmicos atuantes na área de avaliação pós-ocupação. Além disso, o protocolo foi utilizado por uma equipe externa, para processar dados de avaliações pós-ocupação coletados no projeto REFTECHAB, da Universidade Federal de Santa Catarina (UFSC), integrante da Rede 1 do Programa Habitare, referentes a empreendimentos PAR e PSH de Santa Catarina. Ambas as avaliações indicaram que os dispositivos visuais contribuem para aumentar a transparência dos resultados. No caso da aplicação realizada na UFSC, foi evidenciada a facilidade de aplicação do protocolo.

De uma forma geral, o protocolo contribuiu para a análise integrada de diferentes tipos de dados (qualitativos e quantitativos), com base nas percepções de diferentes clientes, com o uso de diferentes recursos para o processamento dos requisitos (dispositivos visuais e CQ). O principal benefício do protocolo é a integração da percepção dos diferentes clientes, que podem ser analisadas conjuntamente para auxiliar na tomada de decisão.

$\mathrm{O}$ uso de dispositivos visuais possibilitou reunir, organizar, condensar e classificar os dados de maneira estruturada, sintética e transparente, para que eles pudessem ser analisados sistematicamente e também ser comparados a dados de outras fontes

${ }^{8}$ A Rede 1 é intitulada Ciência, tecnologia e inovação para a melhoria da qualidade e redução de custos da habitação de interesse social e foi aprovada segundo a Chamada Pública MCT/FINEP/FNDCT/CAIXA - HABITARE - 01/2006. de evidência. Sua necessidade decorre da dificuldade que as pessoas têm para processar uma quantidade muito grande de informações simultaneamente, principalmente dados qualitativos, cuja subjetividade torna o processamento mais complexo.

$\mathrm{O}$ processamento dos requisitos realizado com base nas melhores e piores características demandou tempo maior $\mathrm{e}$ teve maior detalhamento, porque havia uma grande quantidade de dados de caráter predominantemente qualitativo. Às vezes, as organizações não disponibilizam de equipe ou tempo suficientes para esse tipo de processamento de requisitos. Contudo, a redução dos dados, obtida por meio do processamento proposto, representa um grande benefício para o uso dessas informações em uma análise integrada junto a outros dados. Neste trabalho, por exemplo, 824 requisitos considerados positivos reduziram-se para 68 requisitos, enquanto 590 considerados negativos foram reduzidos para o número de 124 . Os requisitos negativos tiveram menor redução porque muitos expressavam características bem específicas dos empreendimentos, enquanto os positivos apresentaram uma tendência de ter um caráter mais amplo e genérico.

É importante salientar que a essência do caráter qualitativo dos dados deve ser mantida. Cabe aos dados processados proporcionar um entendimento completo do conjunto dos dados, sendo muitas vezes necessário explorar novamente dados qualitativos para entender a relação destes com o todo. O uso desse tipo de processamento com redução de dados foi aplicado parcialmente em pesquisas posteriores (MIRON, 2008; BONATTO, 2010), nos quais foram observados resultados semelhantes.

O uso dos dispositivos visuais para o processamento dos requisitos com os dados de satisfação também apresentou grande benefício. Nesse caso, os requisitos avaliados de nove empreendimentos puderam ser agrupados num mesmo dispositivo visual, possibilitando a análise integrada. Além disso, a hierarquização possibilitou a classificação dos requisitos e dos empreendimentos que apresentaram maior satisfação e aqueles que apresentaram índices de satisfação mais baixos. Essa análise integrada é bastante vantajosa quando comparada a outras formas de análise, como o uso de gráficos de pareto, por exemplo, que demanda a necessidade de vários gráficos para compilar todos os dados.

Outra contribuição importante do protocolo foi a utilização de uma ferramenta que permite integrar as percepções dos diferentes intervenientes. Esse

34 Lima, L. P.; Formoso, C. T.; Echeveste, M. E. S. 
tipo de processamento é importante, uma vez que esses intervenientes devem ter seus interesses considerados na tomada de decisão, e a visualização conjunta das informações permite comparar as visões de todos os envolvidos (BRUCE; COOPER, 2000). O processamento dessas informações com o uso de dispositivos visuais foi de fácil aplicação e permitiu a análise integrada das diferentes percepções, incluindo a comparação com a percepção do cliente final. Essa comparação pode revelar que as prioridades estabelecidas pelos intervenientes são muitas vezes diferentes daquelas apontadas pelo cliente final.

A aplicação da CQ teve um caráter exploratório, buscando avaliar sua aplicação no contexto da HIS. Os benefícios se relacionam aos produtos obtidos em cada etapa do processamento da matriz, tais como a priorização dos requisitos do cliente e a definição e a priorização dos requisitos de projeto. Contudo, muitas dificuldades foram encontradas durante o processamento. Primeiramente, destacam-se os requisitos necessários para alimentar a CQ, que, por serem de caráter qualitativo, demandam um grande esforço de processamento. $\mathrm{O}$ processo poderia ser facilitado se a coleta de dados fosse planejada com vistas à aplicação da $\mathrm{CQ}$, incluindo o desenvolvimento de uma ferramenta mais adequada para a coleta. Também, o uso dessa ferramenta requer a participação de uma equipe multifuncional atuando conjuntamente ao longo de todo o planejamento da CQ (ELDIN; HIKLE, 2003), o que, na prática, dificulta o gerenciamento de trade-offs. Outra dificuldade do uso dessa ferramenta está relacionada ao tamanho, à complexidade e ao tempo dispensado para a construção da CQ, o que havia sido apontado também por outros estudos (TAN; PAWITRA, 2001; DIKMEN; BIRGONUL; KIZILTAS, 2005). Quanto mais requisitos do cliente e do projeto são inseridos na matriz, maior a complexidade e o tempo envolvidos em seu desenvolvimento. Dessa forma, a aplicação dessa ferramenta no processamento de requisitos de EHIS ainda carece de novos estudos.

\section{Conclusões}

O principal objetivo proposto por este trabalho foi alcançado com a proposta do protocolo para o processamento de requisitos do cliente de EHIS. O protocolo apresentado evidencia a relevância de um processamento sistematizado dos requisitos do cliente, que permite apoiar a tomada de decisão no desenvolvimento de empreendimentos, facilitando o processamento e a análise de dados de diversas fontes. Mediante sua aplicação, podem ser integradas as percepções de diferentes clientes, incluindo as necessidades dos usuários finais, apoiando a tomada de decisão dos projetistas, de forma a qualificar o desenvolvimento do produto habitacional. $\mathrm{O}$ desenvolvimento desse protocolo também envolveu a aplicação e a adaptação de técnicas e ferramentas que auxiliaram na análise dos dados, qualitativos e quantitativos, gerando novas formas de processamento de requisitos.

$\mathrm{O}$ uso de dispositivos visuais auxiliou o processamento dos requisitos do cliente final e da percepção de outros clientes do processo, facilitando a sistematização das informações coletadas e a criação de transparência para a apresentação e a análise dos resultados encontrados. Por sua vez, a CQ propiciou a oportunidade de testar uma ferramenta muito utilizada em outros setores da indústria, proporcionando um processamento integrado entre os dados do cliente final e os dos demais clientes. Cabe destacar também que o uso dessa ferramenta buscou integrar a percepção dos intervenientes envolvidos no processo de desenvolvimento de EHIS, no qual eles tendem ainda a atuar de maneira bastante fragmentada.

Assim, o processamento sistematizado proposto através do protocolo consiste na principal contribuição deste estudo, uma vez que envolve um método de integração de diferentes dados, originários de diferentes clientes do processo de desenvolvimento do produto, internos e externos, visando aumentar a geração de valor em EHIS. Com essa proposta, pôde-se identificar os fatores de sucesso, que são as características que o cliente gostaria de ver sempre presente no produto recebido, bem como as oportunidades de melhorias, representadas pelas características dos requisitos, que são insatisfatórias e geralmente geram reclamações. Essas informações são importantes para retroalimentar os tomadores de decisão ao longo do desenvolvimento de EHIS de forma mais sistematizada.

Contudo, existem ainda algumas lacunas a serem preenchidas, tais como:

(a) investigação mais aprofundada sobre as informações necessárias para auxiliar os tomadores de decisão no processo de desenvolvimento do produto EHIS e a forma que elas devem ser processadas para sua aplicação;

(b) desenvolvimento e aperfeiçoamento de instrumentos que possibilitem a coleta de dados mais objetivos e passíveis de priorização, necessários para o processamento da CQ;

(c) realização de estudos que desdobrem as demais matrizes do QFD, buscando ampliar o 
entendimento sobre a aplicação da ferramenta no contexto habitacional; e

(d) investigação de formas de processamento de requisitos para facilitar o trabalho colaborativo entre os profissionais envolvidos na concepção e projeto de EHIS.

\section{Referências}

AKAO, Y. Introdução ao Desdobramento da Qualidade. Tradução: Zelinda Tomie Fujokawa e Seiichiro Takahashi, Belo Horizonte, MG: Fundação Cristiano Ottoni, Escola de Engenharia da UFMG: 1996. $187 \mathrm{p}$

ANUMBA, C. J. et al. Collaborative Project Information Management in a Semantic Web Environment. Engineering, Construction and Architectural Management, v. 15, n. 1, p. 78-94, 2008.

BONATTO, S. F. Proposta de um Modelo para Avaliação de Empreendimentos Habitacionais de Interesse Social a Partir da Percepção de Clientes Finais. 2010. 178 f. Porto Alegre. Dissertação (Mestrado em Engenharia Civil) - Escola de Engenharia, Universidade Federal do Rio Grande do Sul, Porto Alegre, 2010.

BARLOW, J.; OZAKI, R. Achieving 'Customer Focus' in Private Housebuilding: current practice and lessons from other industries. Housing Studies, v. 18, n. 1, p. 87-101, 2003.

BRUCE, M.; COOPER, R. Creative Product Design: a practical guide to requirements capture management. Chinchester: John Wiley, 2000. 217 p.

CAIXA Econômica Federal. Programa de Arrendamento Residencial. Brasília, 2003. Disponível em:

<https://webp.caixa.gov.br/urbanizacao/Publicacao /Texto/programa/PAR.htm>. Acesso em: $20 \mathrm{dez}$. 2011.

DIKMEN, I.; BIRGONUL, M. T.; KIZILTAS, S. Strategic Use of Quality Function Deployment (QFD) in the Construction Industry. Building and Environment, v. 40, n. 2, p. 245-255, fev. 2005.

ELDIN, N.; HIKLE, V. Pilot Study of Quality Function Deployment in Construction Projects. Journal of Construction Engineering and Management, v. 129, n. 3, p. 314-329, jun. 2003.

HAUSER, J. R.; CLAUSING, D. The House of Quality. Harvard Business Review, v. 66, n. 3, p. 63-73, maio/jun. 1988.

HUOVILA, P.; SERÉN, K. J. Customer-Oriented Design for Construction Projects. Journal of Engineering Design, v. 9, n. 3, p. 225-238, 1998.
INTERNATIONAL COUNCIL FOR RESEARCH AND INNOVATION IN BUILDING AND CONSTRUCTION. PERFORMANCE CONCEPT IN BUILDING. In: WORKING WITH THE PERFORMANCE APPROACH IN BUILDING, 1982. Rotterdam. Proceedings... Rotterdam, CIB Publication, 1982.

JIAO, J. R.; CHEN, C. H. Customer Requirement Management in Product Development: a review of research issues. Concurrent Engineering: Research and Applications, v. 14, n. 3, p. 173-185, set. 2006.

KAMARA, J. M.; ANUMBA, C. J.;

EVBUOMWAN, N. F. O. Client Requirements Processing in Construction: a new approach using QFD. Journal of Architectural Engineering, v. 5, n. 1, p. 8-15, mar. 1999.

KAMARA, J. M.; ANUMBA, C. J.; EVBUOMWAN, N. F. O. Process model for Client Requirements Processing in Construction. Business Process Management Journal, v. 6, n. 3, p. 251279, 2000a.

KAMARA, J. M.; ANUMBA, C. J.; EVBUOMWAN, N. F. Establishing and Processing Client Requirements: a key aspect of concurrent engineering in construction. Engineering, Construction and Architectural Management, v. 7, n. 1, p. 15-28, mar. 2000b.

KAMARA, J. M.; ANUMBA, C. J.;

EVBUOMWAN, N. F. O. Capturing Client Requirements in Construction Projects. London: Thomas Telford Publishing, 2002.

KOSKELA, L. An Exploration Towards a Production Theory and Its Application to Construction. 2000, 296 f. Helsinki.Thesis (Doctor of Technology) - Technical Research Centre of Finland - VTT, Helsinki, 2000.

LEITE, F. L. Contribuições para o Gerenciamento de Requisitos do Cliente em Empreendimentos do Programa de Arrendamento Residencial. $179 \mathrm{f}$. 2005. Porto Alegre. Dissertação (Mestrado em Engenharia Civil) - Escola de Engenharia, Universidade Federal do Rio Grande do Sul, Porto Alegre, 2005.

LEPREVOST, J.; MAZUR, G. Quality Infrastructure Improvement: using QFD to manage project priorities and project management resources. International Journal of Quality \& Reliability Management, v. 22, n. 1, p. 10-16, 2005.

36 Lima, L. P.; Formoso, C. T.; Echeveste, M. E. S. 
LIMA, L. P. Proposta de Uma Sistemática para o Processamento de Rrequisitos do Cliente de Empreendimentos Habitacionais de Interesse Social. 178 f. 2007. Porto Alegre. Dissertação (Mestrado em Engenharia Civil) - Escola de Engenharia, Universidade Federal do Rio Grande do Sul, Porto Alegre, 2007.

MEDVEDOVSKI, N. S. Diretrizes Especiais para Regularização Urbanística, Técnica e Fundiária de Conjuntos Habitacionais Populares. In: ABIKO, A. K.; ORNSTEIN, S. W. (Ed.). Inserção Urbana e Avaliação Pós-Ocupação (APO) da Habitação de Interesse Social, São Paulo, SP: FAUUSP, 2002. cap. 6, p. 130-159.

MIGUEL, P. A. C. Evidence of QFD Best Practices for Product Development: a multiple case study. International Journal of Quality \& Reliability Management, v. 22, n. 1, p. 72-82, 2005.

MILES, M. B.; HUBERMAN, A. M. Qualitative Data Analysis: an expanded sourcebook. $2^{\text {nd }}$ ed. Thousand Oaks, Calif.: Sage Publications, 1994. 338 p.

MIRON, L. Proposta de Eiretrizes para o Gerenciamento dos Requisitos do Cliente em Empreendimentos da Construção. 2002. $150 \mathrm{f}$. Porto Alegre. Dissertação (Mestrado em Engenharia Civil) - Escola de Engenharia, Universidade Federal do Rio Grande do Sul, Porto Alegre, 2002.

MIRON, L. I. G. Gerenciamento dos Requisitos dos Clientes de Empreendimentos

Habitacionais de Interesse Social: proposta para o Programa Integrado Entrada da Cidade em Porto Alegre, RS. 2008. Porto Alegre. Tese (Doutorado em Engenharia Civil) - Escola de Engenharia, Universidade Federal do Rio Grande do Sul, Porto Alegre, 2008.

ORNSTEIN, S. W.; CRUZ, A. O. Análise de Desempenho Funcional de Habitações de Interesse Social na Grande São Paulo. In: ENCONTRO

NACIONAL DE TECNOLOGIA DO AMBIENTE CONSTRUÍDO, 8., 2000, Salvador. Anais... Salvador: ANTAC, 2000. v. 2, p. 14391446.
PARIS, C. International Perspectives on Planning and Affordable Housing. Housing Studies, v. 22, n. 1, p. 1-9, 2007.

PORKKA, J. et al. Decision Support tools for Performance Based Building. Performance Based Building Thematic Network, Oct. 2004. Disponível em: <http://cic.vtt.fi/projects/pebbu/index2.html>. Acesso em: 13 jun. 2011.

PRASAD, B. Review of QFD and Related deployment techniques. Journal of Manufacturing Systems, v. 17, n. 3, p. 221-234, 1998.

RIBEIRO, J. L. D.; ECHEVESTE, M. E. S.; DANILEVICZ, A. M. F. A Utilização do QFD na Otimização de Produtos, Processos e Serviços: produtos, processos, serviços. Porto Alegre: FEEng/UFRGS, 2001. 98 p.

ROZENFELD, H. et al. Gestão de

Desenvolvimento de Produtos: uma referência para a melhoria do processo. São Paulo: Saraiva, 2006.

TAN, K. C.; PAWITRA, T. A. Integrating SERVQUAL and Kano's Model into QFD for Service Excellence Development. Managing Service Quality, v. 11, n. 6, p. 418-430, 2001.

ULRICH, K. T.; EPPINGER, S. D. Product

Design and Development. $2^{\text {nd }}$ ed. New York: The McGraw-Hill Companies, 2000.

WERNA, E. et al. Pluralismo na Habitação. 2. Ed. São Paulo: Annablume, 2004. 300 p.

\section{Agradecimentos}

Os autores agradecem à Caixa Econômica Federal de Porto Alegre, pelos dados fornecidos e pelo acesso aos empreendimentos; à Finep, pelo financiamento dos projetos Requali e QualiHIS; ao Conselho Nacional de Desenvolvimento Científico e Tecnológico (CNPq), pela bolsa de mestrado concedida; às empresas participantes do estudo, pela concessão de dados; e aos moradores, por permitir que os pesquisadores entrassem em suas casas para entender um pouco de suas vidas.

\section{Revista Ambiente Construído}

Associação Nacional de Tecnologia do Ambiente Construído

Av. Osvaldo Aranha, $99-3^{\circ}$ andar, Centro

Porto Alegre - RS - Brasil

CEP $90035-190$

Telefone: +55 (51) 3308-4084

Fax: +55 (51) 3308-4054

www.seer.ufrgs.br/ambienteconstruido

E-mail: ambienteconstruido@ufrgs.br 